\title{
HEAT EXCHANGER NETWORK SYNTHESIS CONSIDERING CHANGING PHASE STREAMS
}

\author{
F. S. Liporace ${ }^{a}$, F. L. P. Pessoa ${ }^{\text {, }}$ \\ and E. M. Queiroz ${ }^{b}$, \\ a PETROBRAS/CENPES/EB/SAP \\ Cidade Universitária - Ilha do Fundão \\ 21949-900, Rio de Janeiro, RJ, Brasil \\ (21) 3865-7148 \\ liporace@petrobras.com.br \\ ${ }^{\text {b } D E Q / E s c o l a ~ d e ~ Q u i ́ m i c a / U F R J ~}$ \\ Cidade Universitária - Ilha do Fundão \\ Bloco E \\ mach@eq.ufrj.br \\ Rio de Janeiro, RJ, Brasil \\ (21) $2562-7603$
}

\begin{abstract}
The Pinch Design Method was developed considering one-phase streams, with constant specific heats $(\mathrm{Cp})$ throughout streams' temperature ranges. Its first stage, the determination of utilities targets and pinch point (PP), is ruled by the number of streams, their temperatures and $\mathrm{MCp}$. But, for changing phase streams, the usual description of the $\mathrm{Cp}$ behavior by a constant value can lead to errors in this stage and, hence, in the synthesis one. This work proposes a procedure to deal with these streams and discusses its results through an example involving multicomponent streams. First, bubble (BP) and dew (DP) points of the streams are estimated. Then, changing phase streams are split into sub-streams, using BP and DP as bounds. For each one, an effective $\mathrm{Cp}$ is estimated as the division of the enthalpy change by the respective temperature difference. Results obtained show significant changes on the PP, utilities targets and network proposed structure.

Keywords: pinch design method, multicomponent streams, influence of phase change.
\end{abstract}

\section{NOMENCLATURE}

A heat transfer area, $\mathrm{m}^{2}$

BP bubble point temperature, ${ }^{\circ} \mathrm{C}$

$\mathrm{Cp} \quad$ specific heat, $\mathrm{kJ} / \mathrm{kg}{ }^{\circ} \mathrm{C}$

cu cold utility

D inner diameter, $\mathrm{cm}$

DP dew point temperature, ${ }^{\circ} \mathrm{C}$

G mass flux, $\mathrm{kg} / \mathrm{s} \mathrm{m}^{2}$

$\mathrm{H}^{\prime} \quad$ mass enthalpy, $\mathrm{J} / \mathrm{g}$

h local heat transfer coefficient, $\mathrm{W} / \mathrm{m}^{2}{ }^{\circ} \mathrm{C}$

$\mathrm{h}_{\mathrm{lv}} \quad$ latent heat of vaporization, $\mathrm{J} / \mathrm{kg}$,

$\mathrm{h}_{\mathrm{m}} \quad$ mean heat transfer coefficient, $\mathrm{W} / \mathrm{m}^{2}{ }^{\circ} \mathrm{C}$

hu hot utility

ITC inlet temperature of cold stream, ${ }^{\circ} \mathrm{C}$

ITH inlet temperature of hot stream, ${ }^{\circ} \mathrm{C}$

$\mathrm{l}+\mathrm{v}$ liquid + vapor

M mass flowrate, $\mathrm{kg} / \mathrm{s}$

$\mathrm{MCp}$ heat capacity flowrate, $\mathrm{kW} /{ }^{\circ} \mathrm{C}$

MTD minimum temperature difference, ${ }^{\circ} \mathrm{C}$

OTC outlet temperature of cold stream, ${ }^{\circ} \mathrm{C}$

OTH outlet temperature of hot stream, ${ }^{\circ} \mathrm{C}$

$\mathrm{P}_{1} \quad$ stream pressure, $\mathrm{N} / \mathrm{m}^{2}$

PP pinch point, ${ }^{\circ} \mathrm{C}$

Pr Prandtl number

$\mathrm{Pr}_{1} \quad$ Prandtl number for the liquid

Q heat load, MW

sl saturated liquid

Sv saturated vapor

$\mathrm{T}$ temperature, ${ }^{\circ} \mathrm{C}$

TAC total annual cost, \$/year
$\mathrm{T}_{\mathrm{i}} \quad$ inlet temperature, ${ }^{\circ} \mathrm{C}$

$\mathrm{T}_{\mathrm{o}} \quad$ outlet temperature, ${ }^{\circ} \mathrm{C}$

$\mathrm{v}$ mean fluid flow velocity, $\mathrm{m} / \mathrm{s}$

$\mathrm{x}$ vaporized mass fraction

\section{Greek symbols}

$\sigma \quad$ liquid superficial tension, $\mathrm{N} / \mathrm{m}$

$\Delta \mathrm{H}$ enthalpy change, $\mathrm{kW}$

$\Delta \mathrm{H}^{\prime}$ mass enthalpy change, $\mathrm{J} / \mathrm{g}$

$\rho_{1} \quad$ liquid density, $\mathrm{kg} / \mathrm{m}^{3}$

$\kappa_{1} \quad$ liquid thermal conductivity, $\mathrm{W} / \mathrm{m}^{\circ} \mathrm{C}$

$\mu_{1} \quad$ liquid viscosity, $\mathrm{N} \mathrm{s} / \mathrm{m}^{2}$

$\Delta \mathrm{P}$ pressure difference, $\mathrm{N} / \mathrm{m}^{2}$

$\Delta \mathrm{T}_{\mathrm{w}}$ superheat degree, ${ }^{\circ} \mathrm{C}$

$\rho_{\mathrm{v}} \quad$ vapor density, $\mathrm{kg} / \mathrm{m}^{3}$

$\mu_{\mathrm{v}} \quad$ vapor viscosity, $\mathrm{N} \mathrm{s} / \mathrm{m}^{2}$

\section{INTRODUCTION}

The area of heat exchanger network (HEN) synthesis has evolved a lot since the 80 's. Nowadays, there are two kind of approaches to solve synthesis problems: the mathematical programming approach, which uses MINLP programming and solves the problem in an automatic way, and the thermodynamic approach, in which the Pinch Design Method, PDM (Linnhoff and Hindmarsh, 1983) can be highlighted. Although the PDM presents a solid thermodynamic basis, all the examples so far used considered only 
one-phase streams. In this particular case, the use of a constant specific heat $(\mathrm{Cp})$ value throughout the stream temperature range is the common procedure. In the context of the PDM, the determination of the utilities targets and of the pinch point (PP), which guide the synthesis of the initial HEN with minima consumption of utilities and its structural evolution, is strongly linked to the number of process streams, their inlet and target temperatures and heat capacity flowrates (MCp). When process streams undergo a phase change, the use of the traditional PDM procedure can lead to errors in the targeting and synthesis stages, due to the fact that the use of a constant $C p$ value throughout the temperature range of these kind of process stream no longer represents, correctly, their thermal behavior.

Westphalen and Wolf Maciel (1999) presented an alternative procedure to take into account these changing phase process streams, during only the supertargeting stage. When performing the energy targets estimation, using the Temperature Interval Method, for each temperature interval and for each stream in the interval, the enthalpy is calculated at the initial and final temperatures of the interval, as well as a mean value between these two enthalpies. This last result is compared to the enthalpy evaluated at the mean temperature of the interval and, if both are different according to a specified tolerance, the temperature interval is split using the mean temperature as bound. After the convergence of this procedure, the utilities target estimation is conducted taking into account the great number of temperature intervals generated. This procedure may be suitable for the supertargeting stage, but there are no comments about the synthesis stage in this new context with a great number of temperature intervals, and hence, of process streams.

This work aims to go beyond the supertargeting stage and, by presenting a HEN synthesis Case Study involving multicomponent process streams undergoing phase change, it intends to show their influence on the final results, i.e., final HEN structure. First of all, bubble (BP) and dew (DP) points temperatures of all streams are estimated using the Equation of State of PengRobinson. Then, stream by stream, it is verified if it changes phase completely or not, and then, when there is a phase change, it is split into two or three sub-streams, using the BP and DP as bounds. For each sub-stream, an effective mean $\mathrm{Cp}$ is estimated as the division of the enthalpy change by the respective temperature difference. This approach is better than the traditional one in the thermodynamic sense and makes easier units design, since the desuperheating, subcooling and phase change will occur in different units. An example is used to show the strong influence of the phase change, including modification on the PP, utilities targets and streams' distribution along the PP, hence on the HEN synthesis, which was not accomplished by Westphalen and Wolf Maciel (1999).

\section{EXAMPLE, EQUATIONS AND RESULTS}

This example is reported in Hall et al. (1990). Table 1 presents the original set of process streams.

Table 1. Original set of process streams

\begin{tabular}{|ccccc|}
\hline \multicolumn{5}{|c|}{ Problem Table - Minimum Temperature Difference } \\
(MTD) $=20.0^{\circ} \mathbf{C}$ & \\
\hline Stream & $\mathbf{T}_{\mathbf{i}}$ & $\mathbf{T}_{\mathbf{0}}$ & $\mathbf{M C p}$ & $\mathbf{H}$ \\
\hline 1 & 120.0 & 65.0 & 50.0 & $2,750.0$ \\
2 & 80.0 & 50.0 & 300.0 & $9,000.0$ \\
3 & 135.0 & 110.0 & 290.0 & $7,250.0$ \\
4 & 220.0 & 95.0 & 20.0 & $2,500.0$ \\
5 & 135.0 & 105.0 & 260.0 & $7,800.0$ \\
6 & 65.0 & 90.0 & 150.0 & $-3,750.0$ \\
7 & 75.0 & 200.0 & 140.0 & $-17,500.0$ \\
8 & 30.0 & 210.0 & 100.0 & $-18,000.0$ \\
9 & 60.0 & 140.0 & 50.0 & $-4,000.0$ \\
$\mathrm{cu}$ & 15.0 & 30.0 & ----- & ----- \\
$\mathrm{hu}$ & 330.0 & 250.0 & ---- & ---- \\
\hline
\end{tabular}

Assuming that all streams present the same molar fraction composition and total pressure, as shown in Table 2, and using the Equation of State of Peng-Robinson, the bubble and dew points temperatures (BP and DP) can be calculated and are also presented in Table 2. Table 3 presents the enthalpy and the vaporized mass fraction of a stream, with the specified composition, for all the inlet and target temperatures of Table 1, as well as for the BP and DP, which were calculated using the software Petrox, from Petrobras. 


\section{TECNOLOGIA/TECHNOLOGY}

Table 2. Molar composition, pressure, BP and DP

\begin{tabular}{|c|c|}
\hline \multicolumn{2}{|c|}{ Pressure $=7.0 \mathrm{~atm}$} \\
\hline \hline component & molar fraction \\
n-butane & 0.25 \\
n-pentane & 0.25 \\
n-hexane & 0.25 \\
n-heptane & 0.25 \\
\hline \hline $\mathrm{BP}=110.0^{\circ} \mathrm{C}$ & $\mathrm{DP}=141.4^{\circ} \mathrm{C}$ \\
\hline
\end{tabular}

With the data presented in Tables 1 and 3, the mass flowrate and an effective mean specific heat for each stream can be calculated. For instance, consider the original hot stream 1. From Table 1, $\Delta \mathrm{H}=2,750.0 \mathrm{~kW}$; from Table $3, \Delta \mathrm{H}^{\prime}=\mathrm{H}^{\prime}\left(120.0^{\circ} \mathrm{C}\right)$ - $\mathrm{H}^{\prime}\left(65.0^{\circ} \mathrm{C}\right)=216.6 \mathrm{~J} / \mathrm{g}$; hence $\mathrm{M}=12.7 \mathrm{~kg} / \mathrm{s}$; and since $\mathrm{MCp})_{1}=50.0 \mathrm{~kW} /{ }^{\circ} \mathrm{C}$, then $\left.\mathrm{Cp}\right)_{1}=3.94$ $\mathrm{kJ} / \mathrm{kg}{ }^{\circ} \mathrm{C}$

Of course, this mean $\mathrm{Cp}$ value does not take into account the phase change that is occurring since the whole temperature range was considered. Table 4 summarizes the results for the other streams.

Using the traditional procedure of the PDM and based on the data presented in Table 4, Figures 1 and 2 show the Composite Curves and the Grand Composite Curve, while Table 5 presents the PP temperature and the utilities targets for the Case Study here presented. These results are in agreement with the ones reported in Hall et al. (1990), as it is expected, because they also use the traditional procedure.

Table 3. Vaporized mass fraction and enthalpy

\begin{tabular}{|c|c|c|c|}
\hline $\mathbf{T}$ & Condition & $\mathbf{x}$ & $\mathbf{H}^{\prime}$ \\
\hline 220.0 & vapor & 1.00 & $-1,585.7$ \\
\hline 210.0 & vapor & 1.00 & $-1,611.1$ \\
\hline 200.0 & vapor & 1.00 & $-1,636.3$ \\
\hline 141.4 & vapor & 1.00 & - $1,777.7$ \\
\hline 140.0 & liquid + vapor & 0.93 & - 1,798.3 \\
\hline 135.0 & liquid + vapor & 0.73 & $-1,866.2$ \\
\hline 120.0 & liquid + vapor & 0.25 & $-2,035.5$ \\
\hline 110.0 & liquid & 0.00 & $-2,134.2$ \\
\hline 105.0 & liquid & 0.00 & $-2,148.7$ \\
\hline 95.0 & liquid & 0.00 & $-2,175.7$ \\
\hline 90.0 & liquid & 0.00 & $-2,188.9$ \\
\hline 80.0 & liquid & 0.00 & $-2,214.7$ \\
\hline 75.0 & liquid & 0.00 & - 2,227.3 \\
\hline 65.0 & liquid & 0.00 & $-2,252.1$ \\
\hline 60.0 & liquid & 0.00 & $-2,264.3$ \\
\hline 50.0 & liquid & 0.00 & $-2,288.1$ \\
\hline 30.0 & liquid & 0.00 & $-2,334.0$ \\
\hline
\end{tabular}

Table 4. Mass flowrates and effective mean Cp for the original set of process streams

\begin{tabular}{|c|c|c|c|c|}
\hline Stream & $\mathbf{T}_{\mathrm{i}}$ & $\mathbf{T}_{0}$ & $\Delta \mathbf{H}$ & $\Delta \mathbf{H}^{\prime}$ \\
\hline 1 & 120.0 & 65.0 & $2,750.0$ & 216.6 \\
\hline 2 & 80.0 & 50.0 & $9,000.0$ & 73.4 \\
\hline 3 & 135.0 & 110.0 & $7,250.0$ & 268.0 \\
\hline 4 & 220.0 & 95.0 & $2,500.0$ & 590.0 \\
\hline 5 & 135.0 & 105.0 & $7,800.0$ & 282.5 \\
\hline 6 & 65.0 & 90.0 & $-3,750.0$ & -63.2 \\
\hline 7 & 75.0 & 200.0 & $-17,500.0$ & - 591.0 \\
\hline 8 & 30.0 & 210.0 & $-18,000.0$ & -722.9 \\
\hline 9 & 60.0 & 140.0 & $-4,000.0$ & -466.0 \\
\hline Stream & M & & MCp & Cp \\
\hline 1 & 12.7 & & 50.0 & 3.94 \\
\hline 2 & 122.6 & & 300.0 & 2.45 \\
\hline 3 & 27.1 & & 290.0 & 10.7 \\
\hline 4 & 4.2 & & 20.0 & 4.72 \\
\hline 5 & 27.6 & & 260.0 & 9.42 \\
\hline 6 & 59.3 & & 150.0 & 2.53 \\
\hline 7 & 29.6 & & 140.0 & 4.73 \\
\hline 8 & 24.9 & & 100.0 & 4.02 \\
\hline 9 & 8.6 & & 50.0 & 5.83 \\
\hline
\end{tabular}

As mentioned before, due to the assumed streams' composition and pressure, almost all streams of the original set are changing phase, some of them completely, for instance, streams 4, 7 and 8 , and others only partially (streams 1, 3, 5 and 9). Then, if a constant $\mathrm{Cp}$ value is taken for all the temperature range, there is a distance from reality since the energy is not linear distributed along that range. A better thermodynamic approach is split the stream according to the number of present phases and calculate an effective mean $C p$ value for each sub-range. The BP and DP are used as bounds for this split. For instance, the original hot stream 4 goes from superheated vapor to subcooling liquid. According to the proposed procedure, this hot stream is replaced by 3 new hot streams: the first stream with $\mathrm{T}_{i}=220.0^{\circ} \mathrm{C}$ and $\mathrm{T}_{\mathrm{o}}=141.4^{\circ} \mathrm{C}$ (desuperheating condition); the second stream with $\mathrm{T}_{\mathrm{i}}=141.4^{\circ} \mathrm{C}$ and $\mathrm{T}_{\mathrm{o}}=110.0^{\circ} \mathrm{C}$ (phase change condition); and the last one with $\mathrm{T}_{\mathrm{i}}$ $=110.0^{\circ} \mathrm{C}$ and $\mathrm{T}_{\mathrm{o}}=95.0^{\circ} \mathrm{C}$ (subcooling condition).

Table 5. PP temperature and utilities targets original set of process streams

\begin{tabular}{|ccc|}
\hline $\begin{array}{c}\text { PP temperature } \\
\left({ }^{\mathbf{}} \mathbf{C}\right)\end{array}$ & $\begin{array}{c}\text { Hot utility } \\
(\mathbf{M W})\end{array}$ & $\begin{array}{c}\text { Cold utility } \\
\text { (MW) }\end{array}$ \\
\hline $135.0 / 115.0$ & 20.95 & 7.00 \\
\hline
\end{tabular}




\section{TECNOLOGIA/TECHNOLOGY}

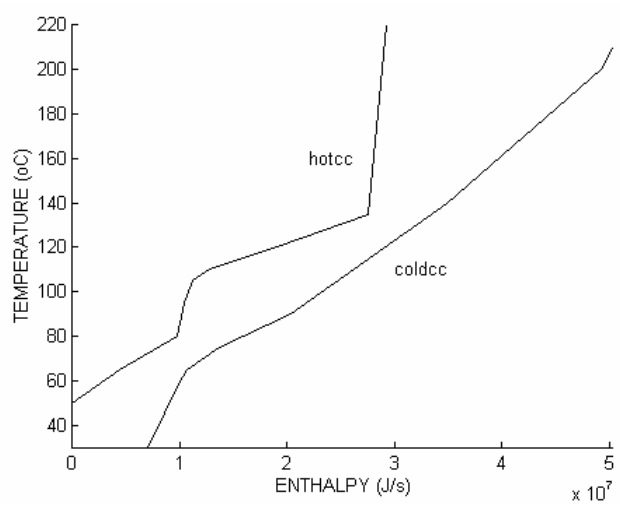

Figure 1. Composite curves - original set of process streams - Hall et al. (1990)

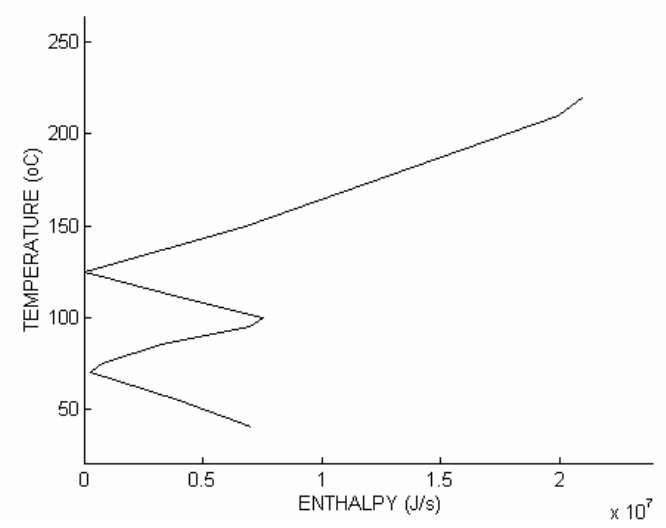

Figure 2. Grand composite curve - original set of process streams - Hall et al. (1990)

For each condition, an effective mean $\mathrm{Cp}$ value is estimated as the division of the enthalpy change by the respective temperature variation, according to the traditional procedure. The advantage, now, is that the energy distribution is no longer considered linear throughout the whole temperature range, but linear distributed in each temperature interval, which at least for the desuperheating and subcooling conditions is a good approximation.

Table 6. New set of process streams

\begin{tabular}{|ccccccccc|}
\hline $\begin{array}{c}\text { New } \\
\text { Stream }\end{array}$ & $\begin{array}{c}\text { Original } \\
\text { Stream }\end{array}$ & $\mathbf{T}_{\mathbf{i}}$ & $\mathbf{T}_{\mathbf{o}}$ & $\Delta \mathbf{H}^{\prime}$ & $\mathbf{M}$ & $\Delta \mathbf{H}$ & $\mathbf{M C p}$ & $\mathbf{C p}$ \\
\hline 1 & 1 & 120.0 & 110.0 & 98.7 & \multirow{2}{*}{12.7} & $1,250.0$ & 125.0 & 9.85 \\
2 & 1 & 110.0 & 65.0 & 117.9 & 12.7 & $1,500.0$ & 33.0 & 2.60 \\
\hline 3 & 2 & 80.0 & 50.0 & 73.4 & 122.6 & $9,000.0$ & 300.0 & 2.45 \\
\hline 4 & 3 & 135.0 & 110.0 & 268.0 & 27.1 & $7,250.0$ & 290.0 & 10.72 \\
\hline 5 & & 220.0 & 141.4 & 192.0 & & 810.0 & 10.0 & 2.36 \\
6 & 4 & 141.4 & 110.0 & 356.5 & 4.2 & $1,510.0$ & 48.0 & 11.33 \\
7 & & 110.0 & 95.0 & 41.5 & & 180.0 & 12.0 & 2.83 \\
\hline 8 & \multirow{2}{*}{5} & 135.0 & 110.0 & 268.0 & \multirow{2}{*}{27.6} & $7,400.0$ & 296.0 & 10.72 \\
9 & & 110.0 & 105.0 & 14.5 & 400.0 & 80.0 & 2.90 \\
\hline 10 & 6 & 65.0 & 90.0 & -63.2 & 59.3 & $-3,750.0$ & 150.0 & 2.53 \\
\hline 11 & & 75.0 & 110.0 & -93.1 & & $-2,760.0$ & 79.0 & 2.67 \\
12 & 7 & 110.0 & 141.4 & -356.5 & 29.6 & $-10,560.0$ & 336.0 & 11.35 \\
13 & & 141.4 & 200.0 & -141.4 & & $-4,190.0$ & 71.0 & 2.40 \\
\hline 14 & & 30.0 & 110.0 & -199.8 & & $-4,970.0$ & 62.0 & 2.49 \\
15 & \multirow{2}{*}{8} & 110.0 & 141.4 & -356.5 & 24.9 & $-8,880.0$ & 283.0 & 11.37 \\
16 & & 141.4 & 210.0 & -166.6 & & $-4,150.0$ & 60.0 & 2.41 \\
\hline 17 & 9 & 60.0 & 110.0 & -130.1 & \multirow{2}{*}{8.6} & $-1,120.0$ & 22.0 & 2.56 \\
18 & 9 & 110.0 & 140.0 & -335.9 & & $-2,880.0$ & 96.0 & 11.18 \\
\hline
\end{tabular}

\section{F. S. Liporace et al. Heat Exchanger Network...}

Table 6 presents the new set of process streams obtained by the proposed procedure. Now, the calculus routine is different from the one used to build Table 4. For instance, consider the new hot stream 1 (first temperature interval of original hot stream 1). From Table 3, $\Delta \mathrm{H}^{\prime}=\mathrm{H}^{\prime}\left(120.0^{\circ} \mathrm{C}\right)-\mathrm{H}^{\prime}\left(110.0^{\circ} \mathrm{C}\right)=98.7 \mathrm{~J} / \mathrm{g}$; hence $\Delta \mathrm{H}^{\prime}=1,250.0 \mathrm{~kW}, \mathrm{MCp}=125.0 \mathrm{~kW} /{ }^{\circ} \mathrm{C}$ and $\mathrm{Cp}$ $=9.85 \mathrm{~kJ} / \mathrm{kg}^{\circ} \mathrm{C}$.

Using data from Table 6 , the utilities targets, as well as the PP temperature, are determined for this new set of process streams, and are shown in Table 7. It can be noted that there are differences among the targets of both sets due to the better energy distribution throughout the temperature range in the new set of process streams. Figures 3 and 4 present the Composite Curves and the Grand Composite Curve for the new set. It can be seen in Figure 4 the possibility of lowpressure vapor generation below the PP, which was not visualized before (refer to Figure 2), represented by a considerable heat source around $100.0^{\circ} \mathrm{C}$.

Table 7. PP temperature and utilities targets - new and original set of process streams

\begin{tabular}{|cccc|}
\hline Case & $\begin{array}{c}\text { PP } \\
\text { temperature } \\
\left({ }^{\circ} \mathbf{C}\right)\end{array}$ & $\begin{array}{c}\text { Hot } \\
\text { utility } \\
(\mathbf{M W})\end{array}$ & $\begin{array}{c}\text { Cold } \\
\text { Utility } \\
(\mathbf{M W})\end{array}$ \\
\hline $\begin{array}{c}\text { original set } \\
\text { (Table 4) } \\
\text { new set } \\
\text { (Table 6) } \\
\text { differences } \\
(\%)\end{array}$ & $135.0 / 115.0$ & 20.95 & 7.00 \\
\hline
\end{tabular}

The difference on the PP temperature and the increase on the number of process streams, will affect the HEN synthesis since there is a modification on the streams' distribution above and below the PP, as shown in Table 8 .

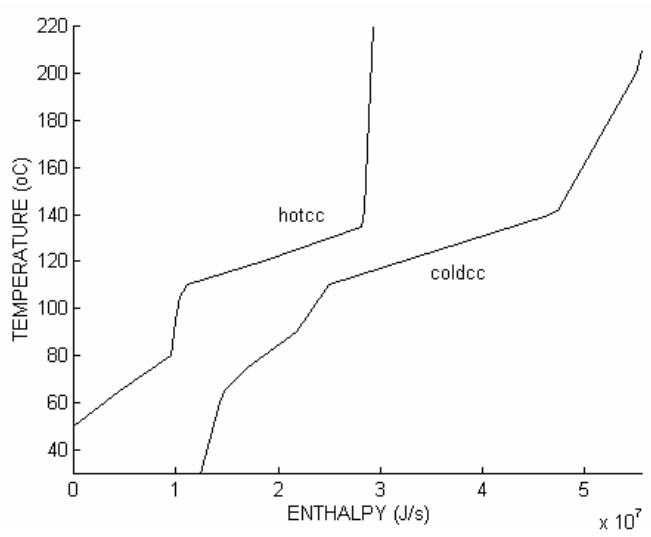

Figure 3. Composite curves - new set of process streams 
TECNOLOGIA/TECHNOLOGY

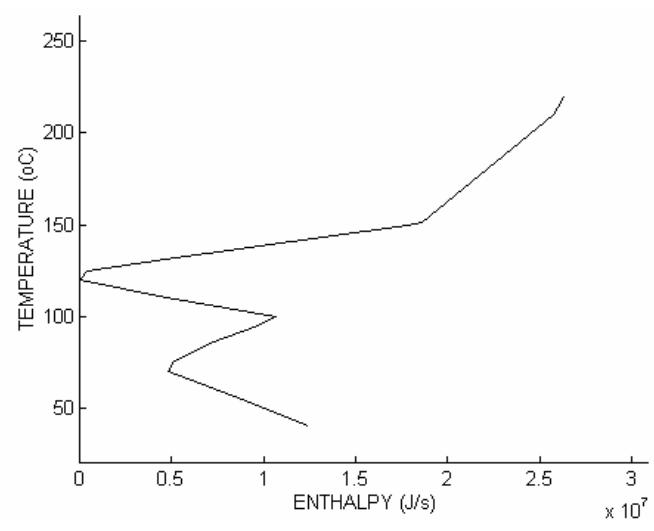

Figure 4. Grand composite curve - new set of process streams

Table 8. Streams' distribution along the PP - new and original set of process streams

\begin{tabular}{|c|c|c|}
\hline Set & original & new \\
\hline hot streams above PP & 1 & 4 \\
\hline cold streams above PP & 3 & 5 \\
\hline hot streams below PP & 5 & 8 \\
\hline cold streams below PP & 4 & 4 \\
\hline
\end{tabular}

In order to show how the final HEN structures will be influenced by the proposed procedure, the capital and operational costs, as well as the heat transfer coefficients for each process streams must be known. The heat transfer coefficients are estimated, according to the stream's condition, using the reported correlations from the literature. In order to use these correlations, it is assumed an inner tube diameter of $3.175 \mathrm{~cm}$ (1 1/4 ") and the local mean fluid flow velocity in each stream is calculated as a function of its mass flux $G$, which is estimated for one temperature (density) and is kept constant for all the temperature range, no matter if the stream changes phase or not.

- for one-phase stream, the well-known DittusBoelter, Eq. (1):

$$
\mathrm{Nu}_{\mathrm{d}}=0.023 \operatorname{Re}_{\mathrm{d}}^{0.8} \operatorname{Pr}^{\mathrm{n}}
$$

where $\mathrm{n}=0.3$ for cooling and $\mathrm{n}=0.4$ for heating; $\mathrm{Re}_{\mathrm{d}}$ is the Reynolds number, $\mathrm{Nu}_{\mathrm{d}}$ is the Nusselt number and Pr is the Prandtl number.

- convective condensation (Traviss et al., 1973), Eqs. (2) to (5):
F. S. Liporace et al. Heat Exchanger Network...

$$
\begin{aligned}
& \frac{\mathrm{h} \mathrm{D}}{\kappa_{1}}=\frac{0.15 \operatorname{Pr}_{1} \operatorname{Re}_{1}^{0.9}}{\mathrm{~F}_{\mathrm{t}}}\left[\frac{1}{\mathrm{X}_{\mathrm{tt}}}+\frac{2.85}{\mathrm{X}_{\mathrm{tt}}^{0.476}}\right] \\
& \operatorname{Re}_{1}=\frac{\mathrm{G}(1-\mathrm{x}) \mathrm{D}}{\mu_{1}} \\
& \mathrm{X}_{\mathrm{tt}}=\left(\frac{1-\mathrm{x}}{\mathrm{x}}\right)^{0.9}\left(\frac{\rho_{\mathrm{v}}}{\rho_{1}}\right)^{0.5}\left(\frac{\mu_{1}}{\mu_{\mathrm{v}}}\right)^{0.1} \\
& \left\{\begin{array}{l}
\mathrm{F}_{\mathrm{t}}=5 \operatorname{Pr}_{1}+5 \ln \left(1+5 \operatorname{Pr}_{1}\right)+2.5 \ln \left(0.0031 \mathrm{Re}_{1}^{0.812}\right) \operatorname{Re}_{1}>1125 \\
\mathrm{~F}_{\mathrm{t}}=5 \operatorname{Pr}_{1}+5 \ln \left[1+\operatorname{Pr}_{1}\left(0.0964 \mathrm{Re}_{1}^{0.585}-1\right)\right] 50<\mathrm{Re}_{1}<1125 \\
\mathrm{~F}_{\mathrm{t}}=0.707 \operatorname{Pr}_{1} \operatorname{Re}_{1}^{0.5} \operatorname{Re}_{1}<50
\end{array}\right.
\end{aligned}
$$

where $\mathrm{h}$ is the local heat transfer coefficient, $\mathrm{D}$ is the tube inner diameter (assumed $3.175 \mathrm{~cm}$ ), $\kappa_{1}$ is the liquid thermal conductivity, $\operatorname{Pr}_{1}$ is the Prandtl number for the liquid, $\mathrm{Re}_{1}$ is the Reynolds number for the liquid, $x$ is the vaporized mass fraction, $G$ is the mass flux, $X_{t t}$ is the Martinelli parameter for the turbulent-turbulent flow, $\rho_{1}$ is the liquid density, $\rho_{\mathrm{v}}$ is the vapor density, $\mu_{1}$ is the liquid viscosity, $\mu_{\mathrm{v}}$ is the vapor viscosity and $F_{t}$ is a parameter.

- convective boiling (Chen, 1987), Eqs. (6) to (14):

$$
\begin{aligned}
& \mathrm{h}=\mathrm{h}_{\text {mac }}+\mathrm{h}_{\text {mic }} \\
& \mathrm{h}_{\text {mac }}=\mathrm{h}_{1} \mathrm{~F}\left(\mathrm{X}_{\mathrm{tt}}\right) \operatorname{Pr}_{1}^{0.296} \\
& \mathrm{~h}_{1}=0.023\left(\frac{\kappa_{1}}{\mathrm{D}}\right) \operatorname{Re}_{1}^{0.8} \operatorname{Pr}_{1}^{0.4} \\
& \operatorname{Re}_{1}=\frac{G(1-x) D}{\mu_{1}} \\
& X_{\mathrm{tt}}=\left(\frac{1-\mathrm{x}}{\mathrm{x}}\right)^{0.9}\left(\frac{\rho_{\mathrm{v}}}{\rho_{1}}\right)^{0.5}\left(\frac{\mu_{1}}{\mu_{\mathrm{v}}}\right)^{0.1} \\
& \left\{\begin{array}{l}
F\left(X_{t t}\right)=1 \quad X_{t t}^{-1} \leq 0.1 \\
F\left(X_{t t}\right)=2.35\left(0.213+\frac{1}{X_{t t}}\right)^{0.736} \quad X_{t t}^{-1}>0.1
\end{array}\right. \\
& \operatorname{Re}_{\mathrm{tp}}=\operatorname{Re}_{1}\left[\mathrm{~F}\left(\mathrm{X}_{\mathrm{tt}}\right)\right]^{1.25} \\
& S\left(\operatorname{Re}_{\text {tp }}\right)=\left(1+2.56 \cdot 10^{-6} \operatorname{Re}_{\mathrm{tp}}^{1.17}\right)^{-1} \\
& h_{\text {mic }}=0.00122\left[\frac{\kappa_{l}^{0.79} C p_{l}^{0.45} \rho_{l}^{0.49}}{\sigma^{0.5} \mu_{l}^{0.29} h_{l v}^{0.24} \rho_{v}^{0.24}}\right] \text {. } \\
& \left(T_{w}-T_{\text {sat }}\left(P_{l}\right)\right)^{0.24}\left(P_{\text {sat }}\left(T_{w}\right)-P_{l}\right)^{0.75} S\left(\mathrm{Re}_{t p}\right)
\end{aligned}
$$

where $\mathrm{h}$ is the local heat transfer coefficient, $\mathrm{h}_{\mathrm{mac}}$ is the macroscopic (convection) 


\section{TECNOLOGIA/TECHNOLOGY}

contribution, $\mathrm{h}_{\text {mic }}$ is the microscopic (nucleate boiling) contribution, $\mathrm{h}_{1}$ is the heat transfer coefficient for the liquid, $\mathrm{Re}_{1}$ is the Reynolds number for the liquid, $\mathrm{x}$ is the vaporized mass fraction, $\mathrm{G}$ is the mass flux, $\mathrm{X}_{\mathrm{tt}}$ is the Martinelli parameter for the turbulent-turbulent flow, $\rho_{1}$ is the liquid density, $\rho_{v}$ is the vapor density, $\mu_{1}$ is the liquid viscosity, $\mu_{v}$ is the vapor viscosity, $\mathrm{Re}_{\mathrm{tp}}$ is the Reynolds number for both phases, $\mathrm{S}$ is the suppression factor, $\mathrm{D}$ is tube inner diameter (assumed $3.175 \mathrm{~cm}$ ), $\kappa_{1}$ is the liquid thermal conductivity, $\operatorname{Pr}_{1}$ is the Prandtl number for the liquid, $\sigma$ is the liquid superficial tension, $\mathrm{h}_{1 \mathrm{v}}$ is the latent heat of vaporization (assumption: $\left.h_{\mathrm{lv}}=\mathrm{H}^{\prime}(\mathrm{BP})-\mathrm{H}^{\prime}(\mathrm{DP})\right), \mathrm{T}_{\mathrm{w}}$ is the wall temperature (assumption: superheating of $\left.10.0^{\circ} \mathrm{C}\right), \mathrm{P}_{1}$ is the stream pressure, $\mathrm{P}_{\text {sat }}\left(\mathrm{T}_{\mathrm{w}}\right)$ is the
F. S. Liporace et al. Heat Exchanger Network...

saturation pressure at $\mathrm{T}_{\mathrm{w}}$ (assumption: it is the pressure where, at $\mathrm{T}_{\mathrm{w}}$, the vaporized mass fraction is the same as the one for the condition $\left[\mathrm{P}_{1}\right.$, stream temperature $]$ ).

These two last correlations were originally developed for pure fluid changing phase, but they will be used for multicomponent streams as a first approximation due to the lack of reported correlations for this special case.

Table 9 presents the estimated heat transfer coefficients for the one-phase process streams. The reported values are the mean ones between the local heat transfer coefficient at the inlet and outlet temperature conditions (local heat transfer coefficient), while Table 10 shows the heat transfer coefficients for the changing phase process streams,

Table 9. Heat transfer coefficients for the new set of process streams (one phase)

\begin{tabular}{|c|c|c|c|c|c|c|c|c|}
\hline Stream & $\mathbf{T}$ & Cond. & $\mathbf{v}$ & G & $\rho$ & $\mu$ & $\operatorname{Pr}$ & $\mathbf{h}_{\mathrm{m}}$ \\
\hline \multirow[b]{2}{*}{2} & 110.0 & $\mathrm{sl}$ & 2.2 & \multirow[b]{2}{*}{$1,201.1$} & 549.0 & $1.34 \times 10^{-4}$ & 4.25 & \multirow[b]{2}{*}{$2,164.0$} \\
\hline & 65.0 & liquid & 2.0 & & 600.6 & $1.85 \times 10^{-4}$ & 4.40 & \\
\hline \multirow[b]{2}{*}{3} & 80.0 & liquid & 2.1 & \multirow[b]{2}{*}{$1,232.4$} & 584.3 & $1.66 \times 10^{-4}$ & 4.34 & \multirow[b]{2}{*}{$2,111.0$} \\
\hline & 50.0 & liquid & 2.0 & & 616.2 & $2.06 \times 10^{-4}$ & 4.50 & \\
\hline \multirow{2}{*}{5} & 220.0 & vapor & 37.9 & \multirow{2}{*}{567.1} & 15.0 & $1.12 \times 10^{-5}$ & 0.81 & \multirow{2}{*}{$2,032.0$} \\
\hline & 141.4 & sV & 29.3 & & 19.3 & $9.64 \times 10^{-6}$ & 0.86 & \\
\hline \multirow{2}{*}{7} & 110.0 & sl & 1.0 & \multirow[b]{2}{*}{567.1} & 549.0 & $1.34 \times 10^{-4}$ & 4.25 & \multirow[b]{2}{*}{$1,222.0$} \\
\hline & 95.0 & liquid & 1.0 & & 567.1 & $1.49 \times 10^{-4}$ & 4.29 & \\
\hline \multirow{2}{*}{9} & 110.0 & sl & 2.0 & \multirow[b]{2}{*}{$1,098.0$} & 549.0 & $1.34 \times 10^{-4}$ & 4.25 & \multirow{2}{*}{$2,094.0$} \\
\hline & 105.0 & liquid & 2.0 & & 555.2 & $1.39 \times 10^{-4}$ & 4.27 & \\
\hline \multirow{2}{*}{10} & 65.0 & liquid & 2.0 & \multirow[b]{2}{*}{$1,201.1$} & 600.6 & $1.85 \times 10^{-4}$ & 4.40 & \multirow[b]{2}{*}{$2,458.0$} \\
\hline & 90.0 & liquid & 2.1 & & 572.9 & $1.55 \times 10^{-4}$ & 4.31 & \\
\hline \multirow{2}{*}{11} & 75.0 & liquid & 1.0 & \multirow{2}{*}{589.8} & 589.8 & $1.72 \times 10^{-4}$ & 4.36 & \multirow{2}{*}{$1,432.0$} \\
\hline & 110.0 & sl & 1.1 & & 549.0 & $1.34 \times 10^{-4}$ & 4.25 & \\
\hline \multirow[b]{2}{*}{13} & 141.4 & SV & 30.5 & \multirow[b]{2}{*}{589.8} & 19.3 & $9.64 \times 10^{-6}$ & 0.86 & \multirow[b]{2}{*}{$2,016.0$} \\
\hline & 200.0 & vapor & 37.2 & & 15.8 & $1.08 \times 10^{-5}$ & 0.82 & \\
\hline \multirow[b]{2}{*}{14} & 30.0 & liquid & 0.8 & \multirow[b]{2}{*}{508.9} & 636.1 & $2.42 \times 10^{-4}$ & 4.71 & \multirow[b]{2}{*}{$1,213.0$} \\
\hline & 110.0 & sl & 0.9 & & 549.0 & $1.34 \times 10^{-4}$ & 4.25 & \\
\hline \multirow[b]{2}{*}{16} & 141.4 & SV & 26.3 & \multirow[b]{2}{*}{508.9} & 19.3 & $9.64 \times 10^{-6}$ & 0.86 & \multirow{2}{*}{$1,810.0$} \\
\hline & 210.0 & vapor & 33.1 & & 15.4 & $1.10 \times 10^{-5}$ & 0.81 & \\
\hline \multirow[b]{2}{*}{17} & 60.0 & liquid & 2.0 & \multirow[b]{2}{*}{$1,211.7$} & 605.8 & $1.91 \times 10^{-4}$ & 4.43 & \multirow[b]{2}{*}{$2,511.0$} \\
\hline & 110.0 & sl & 2.2 & & 549.0 & $1.34 \times 10^{-4}$ & 4.25 & \\
\hline
\end{tabular}


Table 10. Heat transfer coefficients for the new set of process streams (changing phase)

\begin{tabular}{|c|c|c|c|c|c|c|c|c|}
\hline Stream & \multicolumn{2}{|c|}{1} & \multicolumn{2}{|r|}{4} & \multicolumn{2}{|c|}{6} & \multicolumn{2}{|r|}{8} \\
\hline $\mathbf{T}$ & 120.0 & 110.0 & 135.0 & 110.0 & 141.4 & 110.0 & \multirow{2}{*}{$\frac{135.0}{1+\mathrm{v}}$} & 110.0 \\
\hline Cond. & $1+v$ & sl & $1+v$ & sl & SV & sl & & sl \\
\hline G & \multicolumn{2}{|c|}{$1,201.1$} & \multicolumn{2}{|c|}{512.7} & \multicolumn{2}{|c|}{567.1} & \multicolumn{2}{|c|}{$1,098.0$} \\
\hline $\mathbf{x}$ & 0.25 & 0.00 & 0.73 & 0.00 & 1.00 & 0.00 & 0.73 & 0.00 \\
\hline$P r_{1}$ & 4.45 & 4.26 & 4.75 & 4.26 & 4.89 & 4.26 & 4.75 & 4.26 \\
\hline$\rho_{1}$ & 547.2 & 548.9 & 543.0 & 548.9 & 540.8 & 548.9 & 543.0 & 548.9 \\
\hline$\rho_{\mathbf{v}}$ & 18.1 & 17.7 & 18.9 & 17.7 & 19.3 & 17.7 & 18.9 & 17.7 \\
\hline$\mu_{I}$ & $1.35 \times 10^{-4}$ & $1.34 \times 10^{-4}$ & $1.37 \times 10^{-4}$ & $1.34 \times 10^{-4}$ & $1.38 \times 10^{-4}$ & $1.34 \times 10^{-4}$ & $1.37 \times 10^{-4}$ & $1.34 \times 10^{-4}$ \\
\hline$\mu_{\mathrm{v}}$ & $9.55 \times 10^{-6}$ & $9.47 \times 10^{-6}$ & $9.63 \times 10^{-6}$ & $9.47 \times 10^{-6}$ & $9.64 \times 10^{-6}$ & $9.47 \times 10^{-6}$ & $9.63 \times 10^{-6}$ & $9.47 \times 10^{-6}$ \\
\hline$\kappa_{1}$ & 0.086 & 0.087 & 0.083 & 0.087 & 0.082 & 0.087 & 0.083 & 0.087 \\
\hline $\mathbf{h}_{\mathrm{m}}$ & 8,02 & 22.0 & & 23.0 & 7,47 & 76.0 & $\overline{11,9}$ & 952.0 \\
\hline Stream & & 12 & & & & & 18 & \\
\hline $\mathbf{T}$ & 110.0 & & 1.4 & 110.0 & 141.4 & & 0.0 & 140.0 \\
\hline Cond. & sl & & $\mathrm{v}$ & $\mathrm{sl}$ & SV & & 1 & $1+\mathrm{v}$ \\
\hline G & & 589.8 & & & & & $1,211.7$ & \\
\hline $\mathbf{x}$ & 0.00 & & 00 & 0.00 & 1.00 & & 00 & 0.93 \\
\hline $\mathbf{P r}_{1}$ & 4.26 & & 90 & 4.26 & 4.90 & & 26 & 4.83 \\
\hline$\rho_{1}$ & 548.9 & 54 & 0.8 & 548.9 & 540.8 & & 8.9 & 541.3 \\
\hline$\rho_{\mathbf{v}}$ & 17.7 & & .3 & 17.7 & 19.3 & & 7.7 & 19.2 \\
\hline$\mu_{1}$ & $1.34 \times 10^{-}$ & 1.38 & $\mathrm{x} 10^{-4}$ & $1.34 \times 10^{-4}$ & $1.38 \times 10^{-}$ & 1.34 & $\times 10^{-4}$ & $1.38 \times 10^{-4}$ \\
\hline$\mu_{\mathrm{v}}$ & $9.47 \times 10^{-}$ & 9.64 & $x 10^{-6}$ & $9.47 \times 10^{-6}$ & $9.64 \times 10^{-}$ & 9.47 & $\times 10^{-6}$ & $9.64 \times 10^{-6}$ \\
\hline$\kappa_{1}$ & 0.087 & 0. & 82 & 0.087 & 0.082 & 0. & 87 & 0.083 \\
\hline$C p_{1}$ & $2,781.9$ & 2,9 & 12.4 & $2,781.9$ & $2,912.4$ & 2,7 & 31.9 & $2,906.0$ \\
\hline $\mathbf{h}_{\mathrm{lv}}$ & & $.57 \times 10^{5}$ & & 3.57 & $\times 10^{5}$ & & $3.57 \times 10$ & \\
\hline$\Delta \mathbf{T}_{\mathrm{w}}$ & & 10.0 & & & .0 & & 10.0 & \\
\hline$\Delta \mathbf{P}$ & $1.44 \times 10$ & 1.70 & $\times 10^{5}$ & $1.44 \times 10^{5}$ & $1.70 \times 10$ & 1.44 & $\times 10^{5}$ & $1.69 \times 10^{5}$ \\
\hline$\sigma$ & 0.008 & 0.1 & 07 & 0.008 & 0.007 & & & 0.007 \\
\hline $\mathbf{h}_{\mathrm{m}}$ & & $8,611.0$ & & & 0.0 & & $14,566.0$ & \\
\hline
\end{tabular}

which are mean values calculated by $h_{m}=\frac{1}{\left(x_{f}-x_{i}\right)} \int_{x_{i}}^{x_{f}} h(x) d x$, where the integral in numerically evaluated (Gauss-Legendre), and $h(x)$ is represented by the appropriated expressions (Eqs. (2) or (6)). The heat transfer coefficients for the original set of process streams (traditional procedure) are presented in Table 11 and are obtained as follows. Original hot stream 1 is splitted into new hot streams 1 and 2; from Tables 9 and $10, \mathrm{~h}_{1}=8,022.0 \mathrm{~W} / \mathrm{m}^{2 \circ} \mathrm{C}$ and $\mathrm{h}_{2}=2,164.0 \mathrm{~W} / \mathrm{m}^{2 \circ} \mathrm{C}$; from Table $6, \Delta \mathrm{H}_{1}=1,250.0 \mathrm{~kW}$ and $\Delta \mathrm{H}_{2}=1,500.0$ $\mathrm{kW}$, hence the original $\mathrm{h}_{1}$ is $5,072 \mathrm{~W} / \mathrm{m}^{2 \circ} \mathrm{C}$.

Table 11. Heat transfer coefficients for the original set of process streams

\begin{tabular}{|c|c|c|c|}
\hline Stream & $\mathbf{h}_{\mathbf{m}}$ & Stream & $\mathbf{h}_{\mathbf{m}}$ \\
\hline 1 & $5,072.0$ & 6 & $2,458.0$ \\
\hline 2 & $2,111.0$ & 7 & $5,901.0$ \\
\hline 3 & $6,223.0$ & 8 & $4,590.0$ \\
\hline 4 & $5,262.0$ & 9 & $11,191.0$ \\
\hline 5 & $11,447.0$ & & \\
\hline
\end{tabular}

Table 12. Data on costs and heat transfer coefficients for the utilities

\begin{tabular}{|c|c|}
\hline Hot utility (\$/year) & $120,000.0$ \\
\hline Cold utility (\$/year) & $10,000.0$ \\
\hline Investment (\$) & $30,800.0+750.0 \mathrm{~A}^{0.81}$ \\
\hline $\begin{array}{c}\text { rate of return and } \\
\text { equipment life }\end{array}$ & $10.0 \%$ and 6 years \\
\hline $\begin{array}{c}\text { h for hot utility } \\
\left(\mathbf{W} / \mathbf{m}^{2}{ }^{\mathbf{o}} \mathbf{C}\right)\end{array}$ & $4,907.0$ \\
\hline $\begin{array}{c}\text { h for cold utility } \\
\left(\mathbf{W} / \mathbf{m}^{\mathbf{2}}{ }^{\mathbf{o}} \mathbf{C}\right)\end{array}$ & $6,051.0$ \\
\hline
\end{tabular}

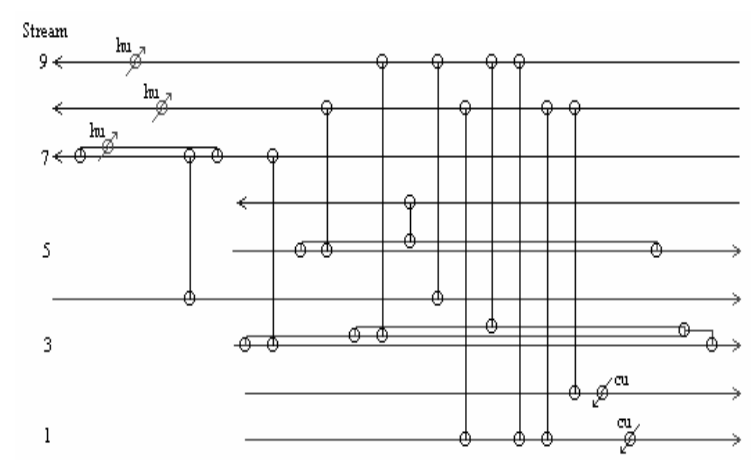

Figure 5. Final HEN for the original set of process streams - TAC: $\$ 2.74$ x 106/year 
Table 12 shows the data on capital and operational costs used in this work and also presents the heat transfer coefficients for hot and cold utilities. The final HEN for the original set of process streams (traditional procedure) is shown in Figure 5 and Table 13 while the final HEN for the new set of process streams (proposed procedure) is presented in Figure 6. Those structures were obtained using the software AtHENS (Automatic Heat Exchanger Network Synthesis), developed at Escola de Química of Universidade Federal do Rio de Janeiro. This software uses a modified PDM rule to perform the synthesis near to the PP and a heuristic rule to synthesize the network away from the PP. After the synthesis of the initial HEN that accomplishes the minima consumption of utilities, the HEN is evolved in order to decrease the HEN TAC. This evolutionary optimization is performed with the help of the Simulation Matrix in order to restore the MTD and the stream's target temperature when they are violated by the loop-breaking procedure (Liporace et al., 1999). As the process streams are not, in fact, split, the HEN structure presented in Figure 6 must be rearranged in order to show the matches of the original streams (Figure 7 and Table 14), so as a comparison between the final HENs obtained by the traditional and proposed procedures can be performed.

Table 13. Data on the HEN presented in Figure 5

\begin{tabular}{|c|c|c|c|c|c|}
\hline Match & ITH & OTH & ITC & OTC & Q \\
\hline hu - 7B & 330.0 & 250.0 & 115.0 & 200.0 & 10.20 \\
\hline $\mathrm{hu}-9$ & 330.0 & 250.0 & 115.0 & 140.0 & 1.25 \\
\hline $\mathrm{hu}-8$ & 330.0 & 250.0 & 115.0 & 210.0 & 9.50 \\
\hline $4-7 \mathrm{~A}$ & 220.0 & 135.0 & 115.0 & 200.0 & 1.70 \\
\hline 3A - 7 & 135.0 & 95.0 & 75.0 & 115.0 & 5.60 \\
\hline 5A - 8 & 135.0 & 94.5 & 74.5 & 115.0 & 4.05 \\
\hline 3B - 9 & 135.0 & 110.0 & 90.0 & 115.0 & 1.25 \\
\hline 5B - 6 & 135.0 & 111.6 & 65.0 & 90.0 & 3.75 \\
\hline $4-9$ & 135.0 & 95.0 & 74.0 & 90.0 & 0.80 \\
\hline $1-8$ & 120.0 & 89.0 & 59.0 & 74.5 & 1.55 \\
\hline $3 \mathrm{C}-9$ & 135.0 & 131.0 & 66.0 & 74.0 & 0.40 \\
\hline $1-9$ & 89.0 & 83.0 & 60.0 & 66.0 & 0.30 \\
\hline $1-8$ & 83.0 & 74.0 & 54.5 & 59.0 & 0.45 \\
\hline $2-8$ & 80.0 & 71.8 & 30.0 & 54.5 & 2.45 \\
\hline $2-\mathrm{cu}$ & 71.8 & 50.0 & 15.0 & 30.0 & 6.55 \\
\hline $1-\mathrm{cu}$ & 74.0 & 65.0 & 15.0 & 30.0 & 0.45 \\
\hline
\end{tabular}

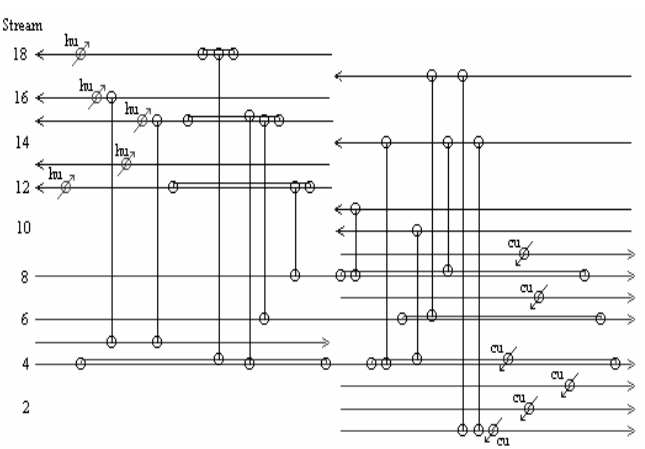

Figure 6. Final HEN for the new set of process streams - TAC: $\$ 3.50 \times 10^{6} /$ year

It must be noted the different matches, splits, number of units and, of course, utilities consumption and TACs between both structures (Figures 5 and 7).

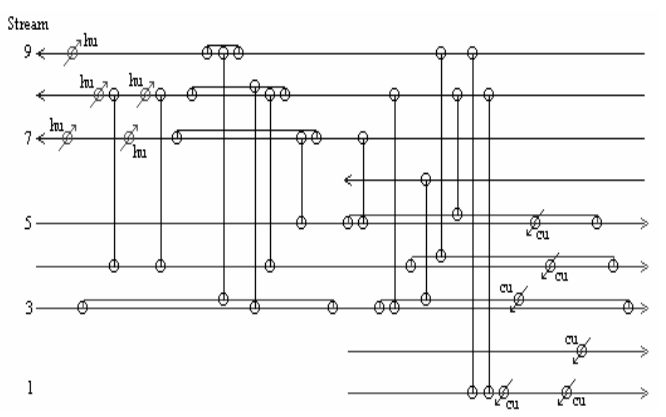

Figure 7. Rearrangement of the HEN structure from Figure 6

Table 14. Data on the HEN presented in Figure 7

\begin{tabular}{|c|c|c|c|c|c|}
\hline Match & ITH & OTH & ITC & OTC & Q \\
\hline $\mathrm{hu}-9$ & 330.0 & 250.0 & 112.9 & 140.0 & 2.60 \\
\hline $\mathrm{hu}-7$ & 330.0 & 250.0 & 141.4 & 200.0 & 4.16 \\
\hline $\mathrm{hu}-8$ & 330.0 & 250.0 & 151.2 & 210.0 & 3.53 \\
\hline $4-8$ & 220.0 & 161.2 & 141.4 & 151.2 & 0.59 \\
\hline $\mathrm{hu}-7$ & 330.0 & 250.0 & 114.4 & 141.4 & 9.07 \\
\hline $\mathrm{hu}-8$ & 330.0 & 250.0 & 116.8 & 141.4 & 6.97 \\
\hline $4-8$ & 161.2 & 141.4 & 116.1 & 116.8 & 0.20 \\
\hline 3B - 9A & 135.0 & 130.0 & 110.0 & 115.0 & 0.28 \\
\hline 3A - 8B & 135.0 & 130.0 & 110.0 & 115.0 & 1.18 \\
\hline $4-8 \mathrm{~A}$ & 141.4 & 130.0 & 110.0 & 121.4 & 0.55 \\
\hline $5-7 \mathrm{~A}$ & 135.0 & 130.0 & 110.0 & 115.0 & 1.48 \\
\hline $5 \mathrm{~A}-7$ & 130.0 & 95.0 & 75.0 & 110.0 & 2.76 \\
\hline 3C - 8 & 130.0 & 110.0 & 90.0 & 110.0 & 1.24 \\
\hline 3D - 6 & 130.0 & 113.6 & 65.0 & 90.0 & 3.75 \\
\hline $4 \mathrm{~B}-9$ & 130.0 & 93.1 & 66.4 & 110.0 & 0.96 \\
\hline 5B - 8 & 130.0 & 115.5 & 39.1 & 90.0 & 3.16 \\
\hline $1-9$ & 120.0 & 118.9 & 60.0 & 66.4 & 0.14 \\
\hline $1-8$ & 118.9 & 114.4 & 30.0 & 39.1 & 0.57 \\
\hline $1-\mathrm{cu}$ & 114.4 & 110.0 & 15.0 & 30.0 & 0.55 \\
\hline $3 \mathrm{D}-\mathrm{cu}$ & 113.6 & 110.0 & 15.0 & 30.0 & 0.81 \\
\hline $5-\mathrm{cu}$ & 110.0 & 105.0 & 15.0 & 30.0 & 0.40 \\
\hline $4-\mathrm{cu}$ & 110.0 & 95.0 & 15.0 & 30.0 & 0.18 \\
\hline $1-\mathrm{cu}$ & 110.0 & 65.0 & 15.0 & 30.0 & 1.49 \\
\hline $2-\mathrm{cu}$ & 80.0 & 50.0 & 15.0 & 30.0 & 9.00 \\
\hline
\end{tabular}




\section{TECNOLOGIA/TECHNOLOGY}

These are due to different PP temperature and streams' distribution through both above and below the PP regions, showing the great influence of a better approach to the energy distribution along the temperature range when there are changing phase process streams. The great number of splits in both HEN is a consequence of the modified PDM rule used to perform the synthesis near to the PP. Another fact that should be mentioned is that, when the HEN of Figure 6 was rearranged, some new loops appeared. As mentioned earlier, splitting a stream using the DP and BP as bounds makes easier the unit design since the desuperheating, subcooling and phase change occur in different units. If these new loops are broken, these phenomena may occur in the same unit, which may increase the difficulties to perform its design. So, in our point of view, they should not be broken. Although the problem size may increase a lot due to the split of some of the process streams, it took AtHENS less than 15 seconds of average computing time (Pentium $166 \mathrm{MHz}$ and $16 \mathrm{MB}$ RAM) to synthesize an initial HEN with minima consumption of utilities and evolve it, for each of the results of the Case Study here discussed.

\section{CONCLUSIONS}

In this work, it is shown how changing phase process streams can significantly interfere on the energy targets and PP estimation and, also, on the final HEN structures in HEN synthesis problems. A procedure to account for these aspects in the supertargeting and synthesis stage is proposed, which is based on the split of the changing phase process streams using the BP and DP as bounds. This approach is better than the traditional one in the thermodynamic sense, due to the better energy distribution along the temperature range, and makes easier the unit design, since the desuperheating, subcooling and phase change will occur in different units.

\section{ACKNOWLEDGEMENTS}

The authors would like to acknowledge the financial support from CAPES and FAPERJ.
F. S. Liporace et al. Heat Exchanger Network...

\section{REFERENCES}

Chen,S.L., Gerner,F.M. and Tien,C.L., 1987, "General film condensation correlations", Exp. Heat Transfer 1, pp. 93-107.

Hall,S.G., Ahmad,S. and Smith,R., 1990, "Capital Cost Targets for Heat Exchanger Networks Comprising Mixed Materials of Construction, Pressure Ratings and Exchanger Types", Comp.Chem.Eng., 14 (3), pp. 319 - 335.

Linnhoff,B. and Hindmarsh,E., 1983, "The Pinch Design Method for Heat Exchanger Networks", Chem. Eng. Sci., 38 (5), pp. 745 - 763.

Liporace,F.S., Pessoa,F.L.P. and Queiroz,E.M., 1999, "Automatic Evolution of Heat Exchanger Networks with Simultaneous Heat Exchanger Design", Brazilian Journal of Chemical Engineering, 16 (1), pp. 25 - 40.

Traviss,D.P., Rohsenow,W.M. and Baron,A.B., 1973, "Forced Convection Condensation in Tubes: A Heat Transfer Correlation for Condenser Design", ASHRAE Trans. 79, Part I, pp. 157-165. Westphalen,D.L. and Wolf Maciel,M.R., 1999, "Pinch Analysis based on Rigorous Physical Properties", Brazilian Journal of Chemical Engineering, 16 (3), pp. 279 - 284. 